\title{
Accuracy of flow measurement with phase contrast MRI in a stenotic phantom: where should flow be measured?
}

\author{
Iman Khodarahmi ${ }^{1 *}$, Mostafa Shakeri ${ }^{1,2}$, Melanie Kotys-Traughber $^{3}$, Stefan Fischer ${ }^{3}$, M Keith Sharp $^{2}$, Amir Amini $^{1}$ \\ From 15th Annual SCMR Scientific Sessions \\ Orlando, FL, USA. 2-5 February 2012
}

\section{Background}

Phase-contrast magnetic resonance imaging (PC-MRI) provides a powerful method for the quantification of blood velocity. Accuracy of flow measurement with PCMRI has been validated with several techniques such as Doppler ultrasound and electromagnetic flowmeters. However, these methods suffer from low accuracy, especially in pulsating flows where short response times are required.

\section{Methods}

Herein, a series of detailed experiments are reported for validation of MR measurements of steady and pulsatile flows with stereoscopic particle image velocimetry (SPIV) on three different stenotic models with $50 \%$, $74 \%$, and $87 \%$ area occlusions. Mean inlet Reynolds number was 190 for both steady and pulsatile cases, mimicking the flow of the human common iliac artery.

Axial PC-MRI images were acquired at three sites: inlet (two diameters proximal to the stenosis), throat, and outlet (two diameters distal to the stenosis) using a 3T TX Achieva Philips MRI scanner with slice thickness $=4 \mathrm{~mm}$, resolution $=1 \times 1 \mathrm{~mm}, \mathrm{TE} / \mathrm{TR}=3.0 / 4.0 \mathrm{~ms}$, field of view $=64 \times 64 \mathrm{~mm}$, and velocity encoding $($ Venc $)=30-200 \mathrm{~cm} / \mathrm{s}$ depending on the imaging section.

For SPIV purposes, a laser light sheet was passed perpendicular to the axis of the phantom to illuminate the flowing fluorescent particles (Fig 1). A set of image pairs were captured using two cameras looking at the phantom at different angles and the fluid velocity was extracted using a cross-correlation scheme, yielding a nominal spatial resolution of $0.2 \mathrm{~mm}$ for the velocity data. The temporal resolution of pulsatile flow measurements was $25 \mathrm{~ms}$, corresponding to 40 measurements per second.

\section{Results}

Agreement between PC-MRI and SPIV was demonstrated for both steady and pulsatile flow measurements at the inlet by evaluating the linear regression between the two methods, which showed a correlation coefficient of $>0.99$ and $>0.96$ for steady and pulsatile flows, respectively.

The difference between SPIV and PC-MRI measurements for steady and pulsatile mean flows was less than $5 \%$ for both inlet and throat and showed good agreement in all cases (Fig 2). The agreement, however, was weaker at the outlet especially for the $87 \%$ stenosis. The flow rate error distal to the stenosis was shown to be a function of narrowing severity.

\section{Conclusions}

Our experiments revealed that the most accurate measures of flow by PC-MRI are found at the throat of the stenosis. This study also illustrates that SPIV provides an excellent approach to in-vitro validation of new or existing PC-MRI flow measurement techniques.

\section{Funding}

This work was supported in part by the National Science Foundation under Grant 0730467 and by an innovative grant from the Clinical and Translational Research Program of the University of Louisville.

${ }^{1}$ Electrical Engineering, University of Louisville, Louisville, KY, USA

Full list of author information is available at the end of the article 


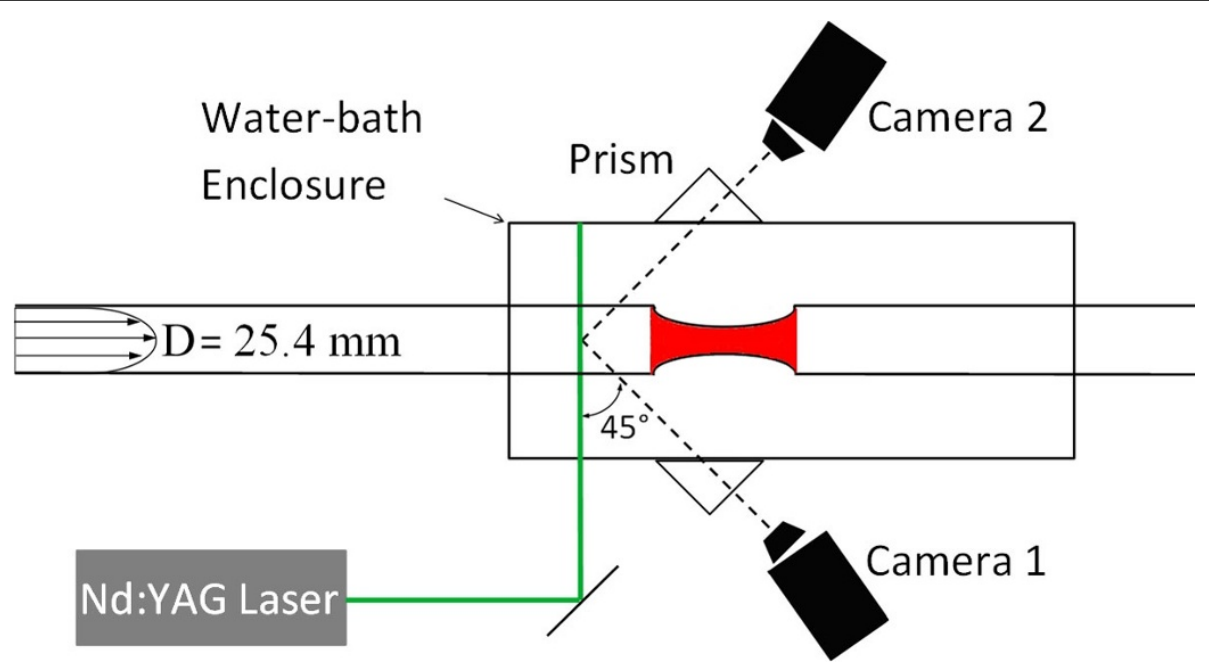

Figure 1 Schematic top view of the SPIV apparatus for flow measurement.

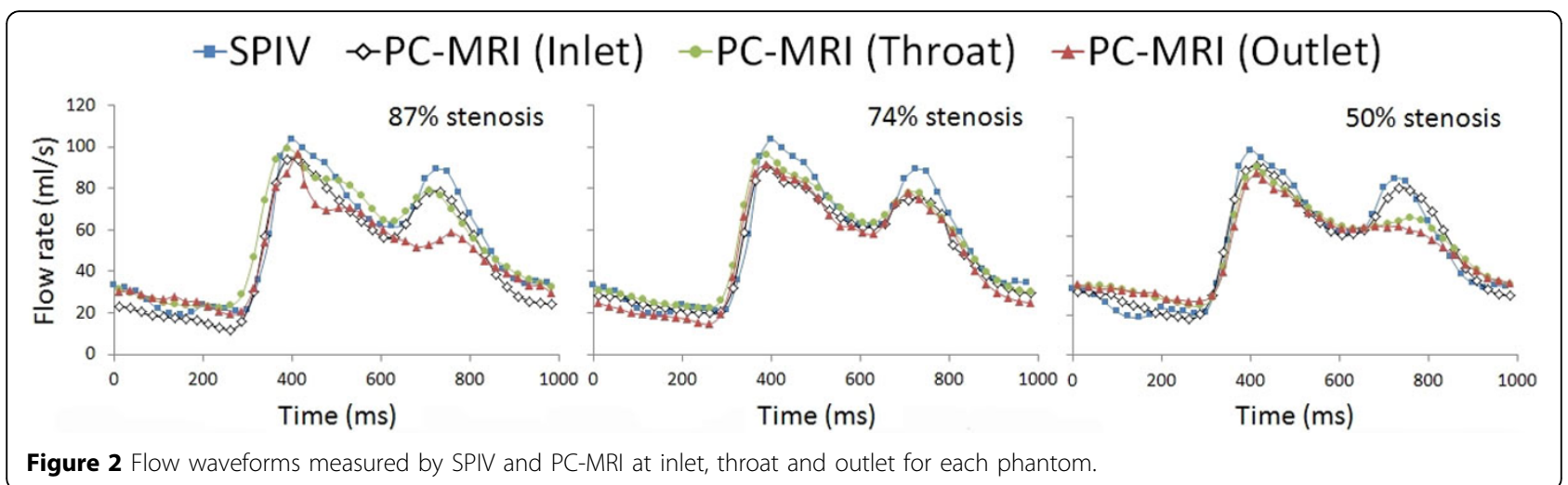

Author details

${ }^{1}$ Electrical Engineering, University of Louisville, Louisville, KY, USA.

${ }^{2}$ Mechanical Engineering, Univeristy of Louisville, Louisville, KY, USA. ${ }^{3}$ MR

Research, Philips Healthcare, Cleveland, OH, USA.

Published: 1 February 2012

doi:10.1186/1532-429X-14-S1-P219

Cite this article as: Khodarahmi et al:: Accuracy of flow measurement with phase contrast MRI in a stenotic phantom: where should flow be measured? Journal of Cardiovascular Magnetic Resonance 2012 14(Suppl 1): P219.
Submit your next manuscript to BioMed Central and take full advantage of:

- Convenient online submission

- Thorough peer review

- No space constraints or color figure charges

- Immediate publication on acceptance

- Inclusion in PubMed, CAS, Scopus and Google Scholar

- Research which is freely available for redistribution 